\title{
An experimental investigation of risk sharing and adverse selection
}

Citation for published version (APA):

Tausch, F., Potters, J. A. M., \& Riedl, A. M. (2013). An experimental investigation of risk sharing and adverse selection. Maastricht University, Graduate School of Business and Economics. GSBE Research Memoranda No. 015 https://doi.org/10.26481/umagsb.2013015

Document status and date:

Published: 01/01/2013

DOI:

10.26481/umagsb.2013015

Document Version:

Publisher's PDF, also known as Version of record

\section{Please check the document version of this publication:}

- A submitted manuscript is the version of the article upon submission and before peer-review. There can be important differences between the submitted version and the official published version of record.

People interested in the research are advised to contact the author for the final version of the publication, or visit the DOI to the publisher's website.

- The final author version and the galley proof are versions of the publication after peer review.

- The final published version features the final layout of the paper including the volume, issue and page numbers.

Link to publication

\footnotetext{
General rights rights.

- You may freely distribute the URL identifying the publication in the public portal. please follow below link for the End User Agreement:

www.umlib.nl/taverne-license

Take down policy

If you believe that this document breaches copyright please contact us at:

repository@maastrichtuniversity.nl

providing details and we will investigate your claim.
}

Copyright and moral rights for the publications made accessible in the public portal are retained by the authors and/or other copyright owners and it is a condition of accessing publications that users recognise and abide by the legal requirements associated with these

- Users may download and print one copy of any publication from the public portal for the purpose of private study or research.

- You may not further distribute the material or use it for any profit-making activity or commercial gain

If the publication is distributed under the terms of Article $25 \mathrm{fa}$ of the Dutch Copyright Act, indicated by the "Taverne" license above, 


\section{Maastricht University}

Franziska Tausch, Jan Potters, Arno Riedl

An experimental investigation of risk sharing and adverse selection

RM/ 13/015

\section{GSBE}

Maastricht University School of Business and Economics

Graduate School of Business and Economics

P.O Box 616

NL- 6200 MD Maastricht

The Netherlands 


\title{
An Experimental Investigation of Risk Sharing and Adverse Selection
}

\author{
Franziska Tausch · Jan Potters · Arno Riedl *
}

March 15, 2013

\begin{abstract}
Does adverse selection hamper the effectiveness of voluntary risk sharing? How do differences in risk profiles affect adverse selection? We experimentally investigate individuals' willingness to share risks with others. Across treatments we vary how risk profiles differ between individuals. We find strong evidence for adverse selection if individuals risk profiles can be ranked according to first-order stochastic dominance and only little evidence for adverse selection if risk profiles can only be ranked on the basis of second-order stochastic dominance. We observe the same pattern also for anticipated adverse selection. These results suggest that the degree to which adverse selection erodes voluntary risk sharing arrangements crucially depends on the form of risk heterogeneity.
\end{abstract}

Keywords: Adverse Selection · Risk Sharing · Experiments · Risk Heterogeneity

JEL Classification: D81 · C91

*Franziska Tausch: Maastricht University, Department of Economics (AE1) and Netspar, P.O. Box 616, 6200 MD Maastricht, the Netherlands, f.tausch@maastrichtuniversity.nl; Arno Riedl: CESifo, IZA, Netspar and Maastricht University, Department of Economics (AE1), a.riedl@maastrichtuniversity.nl; Jan Potters: CENter, Tilburg Univerity and Netspar, j.j.m.potters@uvt.nl. Financial support by Netspar is gratefully acknowledged. 


\section{Introduction}

Adverse selection can undermine the viability of voluntary social insurance and risk sharing arrangements. In case individuals with the most favorable risk profile are unwilling to join a risk pool, those with the next most favorable risk profile will also be unwilling to join and so on. In the end, only those individuals with the least attractive risk profile will be part of the risk sharing arrangement. This mechanism of (unraveling) adverse selection is often advanced as an argument in favor of mandatory participation in social insurance and similar risk sharing schemes.

Despite its key role in the economics of insurance and risk sharing, the empirical evidence for the force of adverse selection is not particularly strong. Fenger (2009) studies some European countries in which individuals have attained the possibility to limit their participation in welfare schemes, such as health policies, unemployment policies and pension schemes. He concludes that there is no convincing evidence for adverse selection. The results for private insurance markets are more ambiguous, with evidence for adverse selection in some markets (health insurance, annuities), but not in others (life insurance, long term care). It is not clear why the evidence is mixed. One possibility is that very risk averse individuals not only have a higher demand for insurance, but may also behave more cautiously. A favorable risk profile may then go hand-inhand with a high insurance coverage (Cutler et al., 2008). It may also be that individuals do not really know how their risk profile compares to that of others, in which case the scope for adverse selection is seriously reduced (Cohen and Siegelman, 2010).

In this paper we use laboratory experiments to investigate the behavioral relevance of adverse selection. A major advantage of the experimental approach is randomization. Decision makers can be randomly assigned to risk profiles thus ruling out any endogeneity bias. Another advantage is that participants can be informed on how their risk profile compares to that of others, so that this cannot be an obstacle for adverse selection. Even under these circumstances, however, it is still an open question whether selection effects will actually occur. Adverse selection places rather strong demands on the rationality of individuals. It relies on their ex-ante ability to predict whether a risk sharing arrangement will lead to favorable redistribution ex-post. To do so requires them to anticipate the risk sharing decisions of others, and to adjust their own decisions accordingly. Moreover, the literature on social preferences (e.g. Fehr and Schmidt, 1999) suggests that even participants with a favorable risk profile may be willing to subsidize, in expectation, those with less favorable prospects.

In our experiment we implement a setup in which three individuals simultaneously decide whether they want to share their risks. Risks are simple two-outcome lotteries, and realizations are independent across players. Individuals make sharing decisions before the risks materialize. 
Those individuals who decide to share their risks, divide (proportionally) the sum of the realized incomes among themselves. Across treatments we implement different forms of risk heterogeneity by varying the two outcomes of the lotteries and/or the corresponding probabilities. Lotteries can vary in mean outcomes (leading to first-order stochastic dominance relations), vary in spread (leading to second-order stochastic dominance relations), or vary in both mean and spread (with a potential conflict between the two). Risk profiles are common knowledge.

Our results display strong evidence for adverse selection in settings in which risk profiles can be ranked on the basis of first-order stochastic dominance. Individuals with a good risk are much less willing to enter a risk sharing arrangement than individuals with a bad risk. In addition, there is clear evidence for strategic adverse selection, which leads to unraveling. Individuals with an intermediate risk anticipate adverse selection of good risks and are in consequence less willing to share risk in this heterogeneous setting compared to a setting in which all individuals have the same (intermediate) risks. At the same time, our results display little evidence for adverse selection in case risks can only be ranked according to second-order stochastic dominance. When the bad risk is a mean-preserving spread of the good risk, this is no cause for adverse selection. Hence, what mainly seems to matter for adverse selection is differences in mean, not differences in spread.

Two other results are noteworthy. First, even though the observed comparative statics coincide with the (calibrated) predictions, the level of adverse selection is much less pronounced than might be expected. Second, even in case risk profiles are identical, so that adverse selection cannot be an issue, the overall level of voluntary risk sharing is lower than predicted.

We are not the first who experimentally study risk sharing, but to the best of our knowledge we are the first to study adverse selection. One of the earliest studies on risk sharing is Selten and Ockenfels (1998), who implement a three-player setting in which all players have the same probability of winning some income. Before the risks materialize, players decide simultaneously how much they will give to the losing player(s) in case they win. Their results indicate that a majority of the winners are willing to transfer money to the loser(s). Several papers build on this so-called solidarity game and study, for instance, the role of group size (Chaudhuri et al., 2010) or the role of reciprocity in a repeated setting (Charness and Genicot, 2007). An important feature of these papers is that the transfer decision is made conditional on being a winner. In this sense, risk sharing is ex-post, which is an important difference with our design where risks are shared ex-ante and decisions cannot be conditioned on the realization of risks.

Barr and Genicot (2008) conduct a field experiment in Zimbabwe where individuals can choose whether or not to share their stochastic income with other members of a group before risks are realized. An important difference with our paper is that risk profiles are endogenous: subjects 
choose from a set of lotteries before they decide about risk sharing. Moreover, the authors focus on the effect of commitment and examine what happens to the level of risk sharing if participants have the option to opt out after the incomes are realized. This is quite different from our paper which focuses on adverse selection, that is, not participating in risk sharing before incomes are realized.

\section{Design and Procedures}

We implement four treatments that differ with respect to the risks that are assigned within sharing groups. Individuals are informed about their own and others' risk exposure, but face unertainty about the actual outcome of the risks when making their decision about how much risk to share with their group members. This depicts an intermediate position between what John Rawls calls and individual's 'original position' behind the veil of ignorance and that beyond the veil (see Rawls, 1971). We first describe the lottery assignment process and point out treatment differences. We then proceed with describing the risk sharing procedure and the experimental procedures including the elicitation of risk preferences.

\subsection{Lottery Assignment}

At the beginning of a session each participant is randomly assigned to one of the four treatments and a matching group with two other participants. Each of them faces a lottery that eventually results in a high income $Y_{i}^{H}$ with probability $p_{i}$ or a low income $Y_{i}^{l}$ with probability $\left(1-p_{i}\right)$. The exact specification of the parameters depends on the treatment and which of three possible lottery types an individual is assigned to.

Table 1 gives an overview of the different lotteries seperated by treatment. It specifies $p_{i}$,

$Y_{i}^{H}, Y_{i}^{l}$, as well as the expected lottery value $\mu$ and the lottery spread $\delta$. The design of our treatments allows to investigate voluntary risk sharing under different forms of risk heterogeneity. In particular, we can observe to what extent the occurence of selection effects hampers the effectiveness of risk sharing and to what extent risk sharing is reduced compared to a situation where risks are homogeneous. In the benchmark $H O$ treatment all participants face identical risks. Risk sharing thus implies that income is redistributed from the fortunate to the less fortunate individuals ex-post. In the $H E \delta$ treatment individuals also face the same $\mu$, however, lottery spreads are different with $\delta_{1}>\delta_{2}>\delta_{3}$ which implies second-order stochastic dominance between lotteries. In the $H E \mu$ treatment expected lottery values differ with $\mu_{1}>\mu_{2}>\mu_{3}$, so that the above average risk of some individuals can be expected to be spread across the sharing group. Individuals face different probabilities for the same possible lottery outcomes. The $H E \mu \delta$ 
Table 1: Treatments

\begin{tabular}{|c|c|c|c|c|c|c|c|c|c|c|c|}
\hline$H O$ & $\mathrm{p}$ & $\mathrm{Y}_{i}^{H}$ & $\mathrm{Y}_{i}^{l}$ & $\mu$ & $\delta$ & $H E \delta$ & $\mathrm{p}$ & $\mathrm{Y}_{i}^{H}$ & $\mathrm{Y}_{i}^{l}$ & $\mu$ & $\delta$ \\
\hline Type 1 & 0.5 & 130 & 20 & 75 & 110 & Type 1 & 0.5 & 150 & 0 & 75 & 150 \\
\hline Type 2 & 0.5 & 130 & 20 & 75 & 110 & Type 2 & 0.5 & 130 & 20 & 75 & 110 \\
\hline Type 3 & 0.5 & 130 & 20 & 7 & 110 & Type 3 & 0.5 & 110 & 40 & 75 & 70 \\
\hline$H E \mu \delta$ & $\mathrm{p}$ & $\mathrm{Y}_{i}^{H}$ & $Y_{i}^{l}$ & $\mu$ & $\delta$ & $H E \mu$ & $\mathrm{p}$ & $\mathrm{Y}_{i}^{H}$ & $\mathrm{Y}_{i}^{l}$ & $\mu$ & $\delta$ \\
\hline Type 1 & 0.5 & 216 & 0 & 108 & 216 & Type 1 & 0.8 & 130 & 20 & 108 & 110 \\
\hline Type 2 & 0.5 & 130 & 20 & 75 & 110 & Type 2 & 0.5 & 130 & 20 & 75 & 110 \\
\hline Type 3 & 0.5 & 52 & 32 & 42 & 20 & Type 3 & 0.2 & 130 & 20 & 42 & 110 \\
\hline
\end{tabular}

treatment combines the previous two forms of risk heterogeneity. The means as well as the lottery spreads are different across group members with $\mu_{1}>\mu_{2}>\mu_{3}$ and $\delta_{1}>\delta_{2}>\delta_{3}$. In order to make treatments comparable, the overall expected income within a risk sharing group is the same for all treatments. Moreover, the expected lottery values are identical in treatments $H E \mu$ and $H E \mu \delta$ for each lottery type. Importantly, the risk exposure of lottery type two is identical across treatments.

\subsection{Risk Sharing Mechanism}

Individual lotteries are public information to all group members. Each participant is asked to choose a risk sharing level $s_{i} \in[0,1]$ which represents the fraction of his eventual income that is placed in the group account $G=\sum_{i=1}^{3}\left(s_{i} \cdot Y_{i}\right)$. This group account is then proportionally divided among all group members. An individual's earnings are consequently defined as

$$
\Pi_{i}\left(s_{i}, s_{j}\right)=\left(1-s_{i}\right) \cdot Y_{i}+r_{i} \cdot G
$$

with $r_{i}=\frac{s_{i}}{\sum_{j=1}^{3} s_{j}}$ being the percentage that an individual receives from the group account and which is proportional to the own risk sharing level. The more risk is shared, the more incomes are equalized ex-post. If all individuals choose complete risk sharing, $s_{i}=1$, eventual earnings of al group members will be identical. The total amount earned in a group, however, is uncertain, since risks are not correlated. If all individuals decide not to share risks at all, each participant's earnings will solely depend on his individual lottery outcome. 


\section{$2.3 \quad$ Procedures}

Each participant was randomly assigned to a computer in the laboratory based on a random draw from a pile of numbered cards. Instructions were provided on the computer and a summary of the most important aspects was provided on paper. Thereafter, participants were asked to answer a few comprehension questions concerning the group account, individual payments, returns and final incomes in order to ensure their understanding of the risk sharing mechanism. When all subjects had correctly answered the questions, the experiment was started. Participants were asked to make risk sharing decisions in three consecutive periods in the same treatment. The group constitution changed in each period as well as the assigned lottery type, so that each participant was assigned each lottery type once. No feedback about lottery outcomes or sharing decisions was provided until the very end of the experiment. At the end of the experiment a random mechanism determined which of the three periods would be relevant for payment.

In addition to the risk sharing decisions in each period we also elicited subject's beliefs about the other group members' decisions by asking them to state the intervals they expect the sharing decision of the other two group members to be in. Belief elicitation was incentiviced using the interval scoring rule (Schlag and van der Weele, 2009). If the actual sharing decision lay between the intervall borders $I_{l}$ and $I_{H}$, the participant was rewarded based on its length: the smaller the interval, the higher the payoff. If the actual decision was outside the interval the participant's payoff was zero. For our analysis we calculated an individual $i$ 's belief about individual $j$ 's risk sharing level as $\hat{s}_{j}=\frac{I_{j H}+I_{j l}}{2}(i \neq j)$.

In the second part of the experiment we elicited individuals' risk preferences. 11 We applied the multiple choice list method (Harrison and Cox, 2008). Certainty equivalents were elicited for the seven different lotteries that subjects could face in the first part. For each lottery individuals were asked to make 20 choices between a sure amount and the respective lottery. The sure amount varies between $Y_{i}^{H}$ and $Y_{i}^{l}$. Certainty equivalents are calculated as the arithmetic mean of the smallest sure amount preferred to the lottery and the consecutive sure amount on the list. Each individuals' risk attitude $\alpha$ was then computed by minimizing the squared distances between the certainty equivalents observed and those theoretically predicted by expected utility theory assuming a utility function for money $U(x)=x^{\alpha}$ (see Wakker, 2008, Wakker, 2010). That is:

$$
\min _{\alpha} \sum_{i=m}^{7}\left[\left(p_{m}\left(Y_{m}^{H}\right)^{\alpha}+\left(1-p_{m}\right)\left(Y_{m}^{l}\right)^{\alpha}\right)^{\frac{1}{\alpha}}-c e_{m}\right]^{2}
$$

with $c e_{m}$ being the elicited certainty equivalent of lottery $m=1, . .7$. The resulting measure $\alpha_{i}=1$ for risk neutral individuals, $\alpha_{i}<1$ for risk averse individuals and $\alpha_{i}>1$ for risk seeking

\footnotetext{
${ }^{1}$ See appendix A.2 for instructions.
} 
individuals.

Lastly, participants were asked to answer a short questionnaire, were provided with information about lottery outcomes and earnings and were then paid in cash and dismissed from the laboratory. Participants were recruited online with the system ORSEE (Greiner, 2004). The computerized experiment was conducted in the Behavioural \& Experimental Economics laboratory of Maastricht University (BEElab) using the experimental software z-tree (Fischbacher, 2007). The experimental earnings were calculated as Experimental Currency Units (ECU) with a conversion rate of $1 \mathrm{ECU}=0.04$ Euros. In total, 120 students participated in the one and a half hour long experiment. Average earnings were approximately 18 Euros.

\section{Theoretical background}

In our experiment each of the three individuals $i=1,2,3$ in a group faces a lottery which leads

to a high income $Y_{i}^{H}$ with probability $p_{i}$ and to a low income $Y_{i}^{l}$ with probability $\left(1-p_{i}\right)$. Each individual indpendendly decides on how much risk to share, by deciding on the share $s_{i}$ of his eventual (ex-post) income he puts into the group account. This share, together with the sum of shares of the other individuals, determines the individual's return from the group account. To make an optimal sharing decision each indivdual has to consider each others (expected) sharing decision.

More formally, denote $\hat{s_{j}}(j \neq i)$ as $i$ 's belief about the other group members' sharing decisions. When making the sharing decision, each indivual has to consider the overall lottery with the eight possible realizations $\Pi_{i k}\left(s_{i}, \hat{s_{j}}\right)(k=1,2, \ldots, 8)$ for the different combinations of high and low incomes together with the expected sharing decisions of others. Each of these possible realizations is given by

$$
\Pi_{i k}\left(s_{i}, \hat{s_{i}}\right)=\left(1-s_{i}\right) \cdot Y_{i k}+\frac{s_{i}}{s_{i}+\sum_{j \neq i} \hat{s_{j}}} \cdot\left(\sum_{j \neq i} \hat{s_{j}} \cdot Y_{j k}+s_{i} \cdot Y_{i k}\right),
$$

where $Y_{i k}$ denotes individual $i$ 's ex-post income (high or low) in the $k^{\text {th }}$ realization. Denote $p_{k}$ as the probability with which each of the eight realizations occur, then an expected utility maximizing individual $i$ chooses $s_{i}$ such that

$$
\max _{s_{i}} E U_{i}=\sum_{k=1}^{8} p_{k} \cdot U\left[\Pi_{i k}\left(s_{i}, \hat{s_{j}}\right)\right] .
$$

Assume that individuals' risk preferences can be represented by the power utility function $U(x)=x^{\alpha}$. Then it can be shown that in treatment $H O$ full risk sharing $(s 1=s 2=s 3=1)$ is an equilibrium for all $\alpha<1$. In $H E \delta$ joint risk sharing $\left(s_{1}>0, s_{2}>0, s_{3}>0\right)$ is an equilibrium for all $\alpha<1$ whereas in $H E \mu \delta$ it is an equilibrium only for some $\alpha<1$. Finally, in $H E \mu$ joint 
risk sharing is never an equilibrium because the lowest risk type will never share $\left(s_{1}=0\right)$. Hence, in the aggregate we expect that joint risk sharing is highest in $H O$, second highest in $H E \delta$, third highest in $H E \mu \delta$, and lowest in $H E \mu$.

\section{Results}

In this section we first report the aggregate risk sharing decisons and how they change across treatments and lottery types. Second, we compare the empirical results to theoretical benchmark conditions taking into account individual risk preferences and beliefs about others' sharing decisions. Finally, we explore potential strategic adverse selection by investigating how beliefs about other risk sharing decisions affect one's own sharing decision.

\subsection{Risk sharing and adverse selection}

At the moment of their risk sharing decisions subjects do not know the realizations of their lotteries. Hence, a natural measure of aggregate risk sharing is the ex-ante expected amount of money in the group account: the sum over individuals' risk sharing percentages times the expected value of their lotteries $2^{2}$ Using this measure, Figure 1 shows that risk sharing is highest in $H O$ and $H E \delta$, smaller in $H E \mu \delta$ and smallest in $H E \mu$. This is roughly in line with the theoretically predicted ranking, except that risk sharing levels do not differ between $H O$ and $H E \delta$. A Kruskal-Wallis (KW) test indicates that significant differences between treatments exist $(p=0.0347){ }^{3}$ Pair-wise comparisons with Mann-Whitney (MW) tests reveal, that in $H E \mu$ the expected amount in the group account is significantly smaller than in $H O$ and $H E \delta(p \leq 0.0283$; FDR corrected at $10 \%$ level). Other pair-wise comparisons yield weaker significance $(p \geq 0.0758$, FDR corrected insignificant).

\section{Result 1. RISK SHARING AND RISKINESS}

(1) Compared to the theoretical benchmark, too little risk is shared when risk is equally distributed.

(2) As predicted risk sharing decreases with differences in individuals' risk profiles. Specifically, it is smallest when individuals' risk profiles differ according to first-order stochastic dominance.

The reported aggregate sharing decisions conceal considerable differences between different lottery types within and across treatments. However, Figure 2 shows average risk sharing sep-

\footnotetext{
${ }^{2}$ An alternative measure would be the expected amount of transfers implied by a risk sharing scheme. Using this measure leads to similar results but it is considerably more complex to calculate.

${ }^{3}$ Throughout the paper, we correct p-values using the false discovery rate (FDR) whenever we carry out multiple pair-wise comparisons. This method reduces the risk of false positives and controls for the rate of false negatives (Benjamini and Hochberg, 1995). All reported tests are 2-sided.
} 


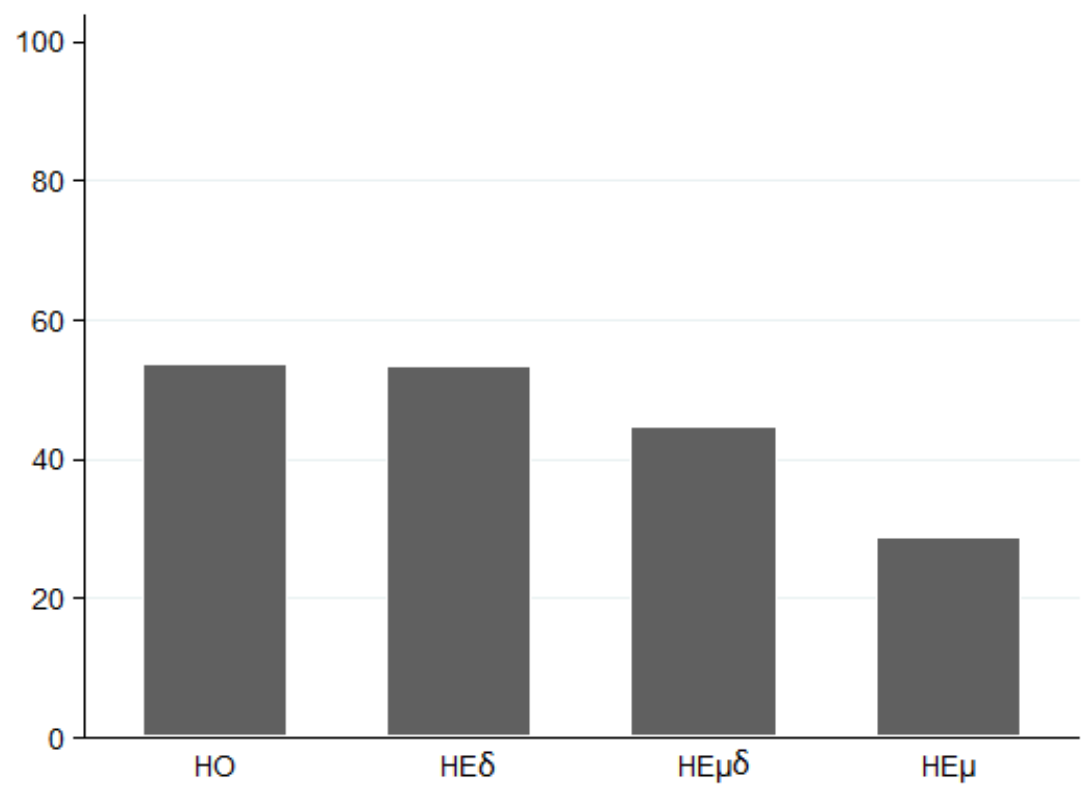

Figure 1: Expected amount in group account (percent)

arately for each lottery type in each treatment. As expected, in $H O$, where all individuals in a group have the same risk profile, a Wilcoxon signed-ranks (WS) test yields that subjects with different labels (i.e, 1, 2, or 3) exhibit statistically indistinguishable risk sharing decisions $(51.7 \%$, $53.3 \%, 52.3 \% ; p \geq 0.992)$.

In $H E \delta$, where individual risk profiles can be ranked according to second-order stochastic dominance, lottery types decrease in their riskiness from left (lottery type 1) to right (lottery type 3). Adverse selection would predict decreasing risk sharing in the same direction. The figure shows that empirically risk sharing is highest when participants are assigned lottery type $2(62.2 \%)$ followed by lottery type $1(55 \%)$ and lottery type $3(47.7 \%)$. A WS test yields that the difference in risk sharing between lottery type 2 and 3 is significant at the FDR-corrected $5 \%$ level $(p=0.013)$. As all other pair-wise comparisons return insignificant results $(p \geq 0.432)$, we consider this as only weak evidence in favor of adverse selection when individuals' risk profiles can be ranked according to second-order stochastic dominance.

In $H E \mu \delta$ and $H E \mu$ results are very different. In both treatments, risk sharing levels of lottery types clearly increase from left (lottery type 1) to right (lottery type 3 ). This correlates negatively with the expected values of the lottery types, which increase from right to left, and clearly indicates the existence of adverse selection when risk profiles can be ranked according to first-order stochastic dominance. Specifically, in $H E \mu$ individuals with the low expected value (bad risk) lottery type 3 choose on average a risk sharing level of $77.4 \%$, those with an intermediate risk profile (lottery type 2) choose a level of $36.5 \%$, and those with a high expected value (good risk) choose a sharing level of only 17.9\%. Pairwise WS tests reveal that differences 


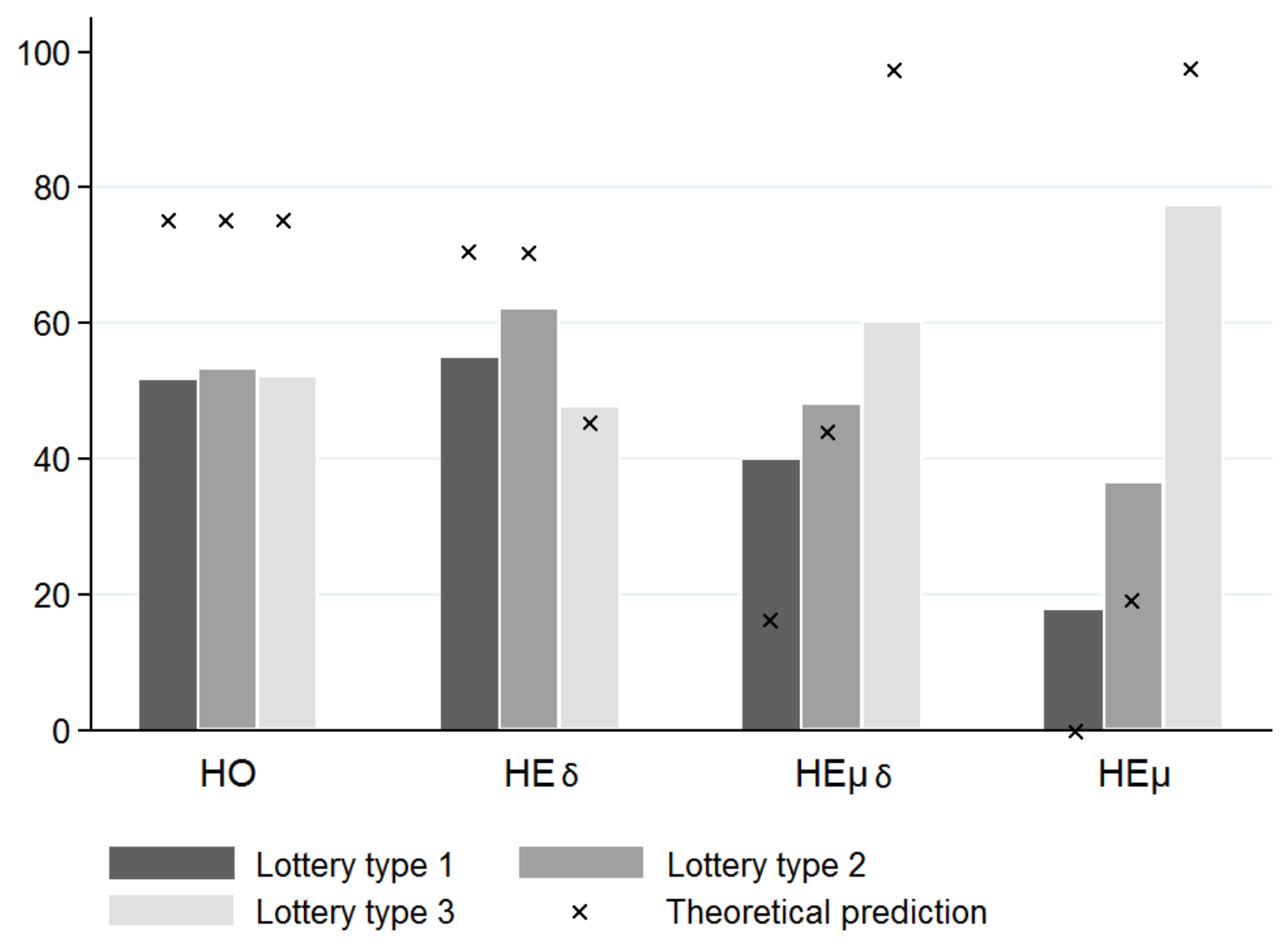

Figure 2: Risk sharing per lottery type (in percent)

between lottery types are statistically significant at the FDR-corrected $5 \%$ level $(p \leq 0.001)$. With a difference of about 60 percentage points between the low and high expected value lottery type, adverse selection effects are also of economic significance.

In $H E \mu \delta$ risk increases from left (lottery type 1) to right (lottery type 3 ) in terms of expected values but decreases in terms of outcome spreads. ${ }^{4}$ Hence, regarding adverse selection effects, individuals' ranking of risk profiles according to first- and second-order stochastic dominance work in opposite directions. These countervailing effects on adverse selection are empirically reflected by the less extreme differences in sharing across lottery types. As in $H E \mu$, sharing is still highest for lottery type 3 (60.3\%), intermediate for lottery type 2 (48.1\%), and lowest for lottery type 1 (40.1\%). However, the difference between the two extreme lottery types is with 20.2 percentage points less stark than in $H E \mu$ and not all differences are statistically significant. Pair wise comparisons with WS tests show that between lottery type 3 and lottery types 1 and

\footnotetext{
${ }^{4}$ In the following we will refer to the risk of lottery type 1 as the 'good' risk in $H E \mu \delta$ and $H E \mu$, whereas in $H E \delta$ lottery type 3 is the 'good' risk.
} 
2 the differences are statistically significant at the FDR-corrected $5 \%$ level $(p \leq 0.027)$ but not between lottery type 1 and $2(p=0.216)$.

\section{Result 2. AdVERSE SEleCtion AND RISK PROfiles}

(1) If individuals' risk profiles are ranked according to second-order stochastic dominance little adverse selection is observed.

(2) If individuals' risk profiles are ranked according to first-order stochastic dominance there is strong evidence for adverse selection.

(3) The adverse selection effect due to riskiness according to first-order stochastic dominance is mitigated by decreased riskiness due to second-order stochastic dominance.

To get a better idea how the empirical results compare to theoretically predicted behavior we calculated the individually optimal risk sharing levels for each subject for each lottery type using the elicited individual risk preference and beliefs about others sharing decisions 5 Specifically, we assume that the preferences of each subject $i$ can be represented by a utility function for money $U_{i}(x)=x^{\alpha_{i}}$, where the individual risk parameter $\alpha_{i}$ is estimated as described in Section 2.3 . Further, we use the elicited beliefs of $i$ about others' sharing decisons $\hat{s_{j}}$ to solve for each $i$ the maximization problem in Equation (3), given the possible realizations in Equation (2).

In Figure 2 the black crosses indicate the average of these individually optimal risk sharing levels. Two regularities are immediately eye-catching. First, for each treatment, across types the changes in sharing levels fit the theoretical comparative statics results qualitatively very well. 'Bad' risk lottery types are predicted to share more than intermediate risk lottery types than 'good' risk lottery types. Second, quantitatively the empirical sharing levels sometimes diverge significantly from the individually optimal ones.

In $H O$ actual risk sharing is significantly lower than theoretically predicted $(p \leq 0.032$ for all lottery types, WS tests). In $H E \delta$, however, empirical risk sharing levels do not differ from predicted ones for any lottery type ( $p \geq 0.128$, WS tests). In $H E \mu$ and $H E \mu \delta$ predicted adverse selection is stronger than it is actually the case. In $H E \mu$, for all three lottery types differences between theoretical and empirical sharing levels are statistically significant ( $p \leq 0.024$, WS tests). In $H E \mu \delta$ differences between theoretically predicted and empirically observed sharing levels are significant for lottery types 1 and 3 ( $p \leq 0.001$, WS tests) but not for lottery type $2(p=0.724$, WS test).

\footnotetext{
${ }^{5}$ Note that this does not give an equilibrium prediction but rather a 'naïve' optimal decision for each individual. We consider such naïve behavior of our subjects as more realistic than equilibrium behavior for at least two reasons. First, the latter would ask for complex computations our subjects unlikely went through. Second, it also requires common knowledge of all individuals risk preferences, information our subjects did not have and also could not acquire as all sharing decisions were only made once.
} 
Result 3. INDIVIDUALLy optimal AND EMPIRICAL ADVERSE SELECTION.

(1) Qualitatively, empirically observed adverse selection coincides with individually optimal adverse selection: risk sharing correlates with risk profiles in the predicted way.

(2) Quantitatively, adverse selection is less pronounced than individually optimal risk sharing would dictate.

\subsection{Anticipated and strategic adverse selection}

An important element of our experimental design is that individuals with an intermediate risk profile (lottery type 2) faced exactly the same individual lottery and, hence, risk exposure in all treatments, whereas the risk profiles of the other lottery types systematically varied across treatments. Moreover, the sum of the expected values of lottery types 1 and 2 is also identical in all treatments.

In Section 4.1 we have seen that risk sharing of individuals with intermediate risk profile is highest in $H O$ and $H \delta$, lowest in $H \mu$, and intermediate in $H \mu \delta 6$ This strongly suggests that these differences are a response to anticipated adverse selection and, hence, strategic. We use the beliefs that subjects with intermediate risk profiles have about other lottery types' risk sharing to investigate whether adverse selection is indeed anticipated. If so, we should see differences in beliefs of lottery type 2 regarding the other types' risk sharing levels across treatments, which should correlate with actual risk sharing of lottery types 1 and 3 .

Figure 3 reports the average risk sharing levels of lottery types 1 and 3, expected by lottery type 2 . It shows that beliefs about other types are clearly in line with these types' actual behavior (cf. Figure 2). There are no statistically significant differences between type 2's beliefs and the actual behavior of types 1 and 3 ( $p \geq 0.1985$, MW tests). This is corroborated by a regression analysis showing that risk sharing of lottery type 2 individuals is positively correlated with the anticipated risk sharing by the 'good' risk risk lottery type (see Appendix A).

Result 4. Risk PRofiles, ANTICIPATEd AND STRATEgiC ADVERSE SELECTION.

(1) Intermediate risk types, with a constant risk profile, exhibit varying degrees of adverse selection across treatments.

(2) Intermediate risk types exhibit strategic adverse selection as their own adverse selection correlates with their correctly anticipated adverse selection of other risk types.

\footnotetext{
${ }^{6}$ The differences in sharing levels are FDR-corrected (marginally) significant different between $H \mu$ and $H O$ and $H \delta$ and between $H \delta$ and $H \mu \delta$ ( $p \leq 0.0318$, MW tests).
} 


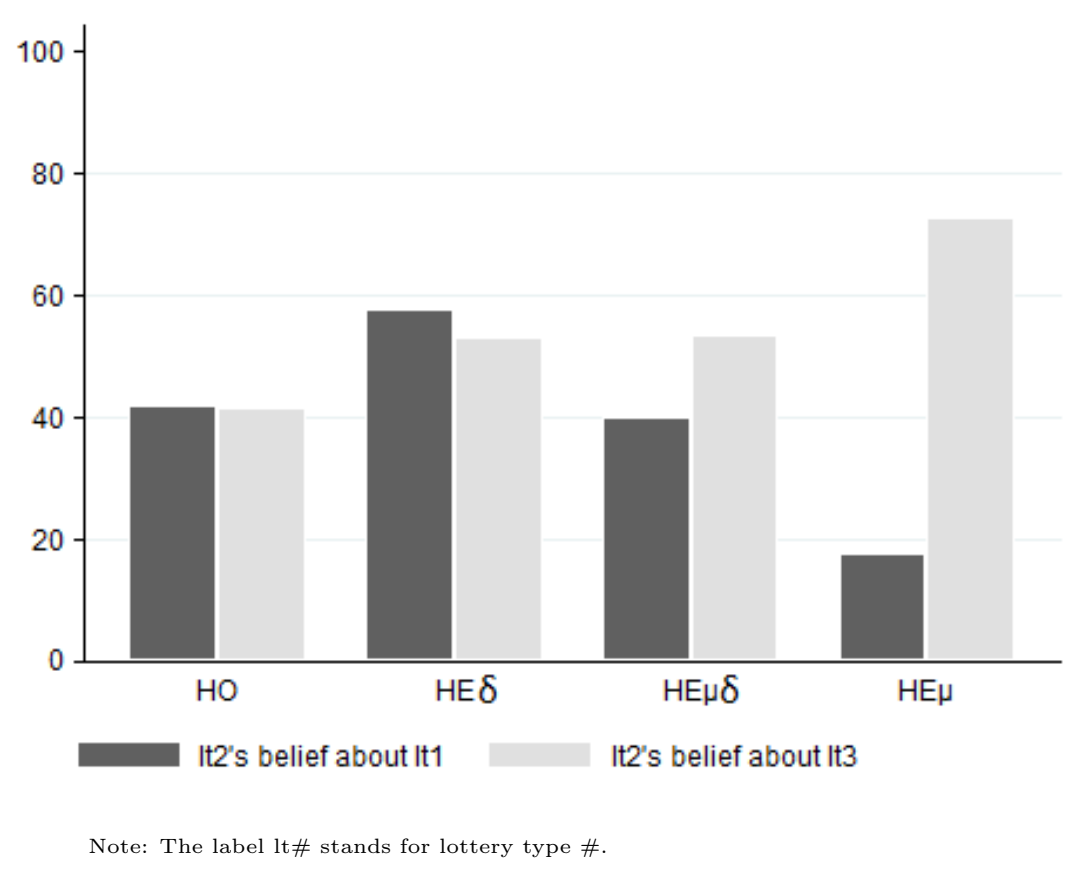

Figure 3: Belief of lottery type 2 about other lottery types' sharing levels (in percent)

\section{Conclusion and Discussion}

We experimentally investigate how heterogeneity in risks affects voluntary risk sharing. Participants are asked to decide how much risk they are willing to share knowing their and others' risk profiles but facing uncertainty about risk outcomes. The results provide behavioral evidence for the relevance of adverse selection. Individuals with a 'good' risk profile are less likely to enter a risk sharing arrangement than individuals with a 'bad' risk profile. The strength of the effect, however, depends on the manner in which the risk profiles vary between individuals. Risks which differ in terms of mean outcomes (first-order stochastic dominance) generate much stronger selection effects than risks which differ by way of mean-preserving spreads (second-order stochastic dominance).

Qualitatively, our results are in line with the theoretical predictions, assuming CRRA utility maximization. The observed treatment effects line up nicely with the theoretical comparative statics. Risk sharing levels are higher in treatments in which risk sharing is an equilibrium under a wider set of parameters. Moreover, calibrated predictions at the individual level using elicited risk preferences and beliefs correlate strongly with observed decisions. Quantitatively, however, point predictions are often off the mark. Specifically, we find that risk sharing levels are generally less extreme than predicted. For example, in a symmetric environment with homogenous risks, risk sharing levels are about 30\%-points lower than predicted. Also, selection effects generally fall short of the prediction. It should be realized, however, that our experiment is single shot, 
and that participants have no opportunity for learning. In future work, it would be interesting to explore how risk sharing and adverse selection develop over time with repeated interaction and with learning.

In many countries there are continuing debates on whether mandatory insurance should be introduced for some risks (think of Obamacare), while in others countries (partial) exit options are being proposed for certain collective arrangements (such as mandatory occupational pension schemes). A key issue in the public debate, at least in Europe, is whether the option to opt out may undermine 'solidarity', where the lucky support the unlucky. Although one must be cautious to generalize from lab to field, our results suggest that such concerns are well-founded behaviorally. At the same time, our results indicate that much will depend on the manner and degree to which risk profiles differ. The easier it is to order different risk profiles from 'good' to 'bad', the stronger selection effects are likely to be.

Finally, one may question whether our design is somehow biased towards finding certain effects. Indeed, in our experiment participants risk profiles are common knowledge. This may lead to an overestimation of the importance of selection for environments in which people do not have very precise knowledge about how their risk profile compares to that of others. On the other hand, however, in our experiment risks profiles are assigned exogenously. This may underestimate the force of adverse selection for settings in which risks are endogenous. The support for redistribution is typically higher in case poverty is caused by bad luck rather than a lack of effort (Cappelen et al., 2012). Similarly, low risk individuals may be (even) less willing to share risk with high risk individuals in case they perceive that those are accountable for their risk (see Cettolin and Tausch, 2013). Future work will have to establish which of these elements are more or less important for the behavioral relevance of adverse selection. 


\section{References}

Barr, A. and Genicot, G. (2008). Risk sharing, commitment and information: An experimental analysis. Journal of the European Economic Association, 6(6):1151-1185.

Benjamini, Y. and Hochberg, Y. (1995). Controlling the false discovery rate: A practical and powerful approach to multiple testing. Journal of the Royal Statistical Society Series B (Methodological), 57:289300.

Cappelen, A. W., Konow, J., Sorensen, E., and Tungodden, B. (2012). Just luck: An experimental study of risk taking and fairness. American Economic Review (forthcoming).

Cettolin, E. and Tausch, F. (2013). Risk sharing and risk taking: does accountability matter? Mimeo.

Charness, G. and Genicot, G. (2007). Informal risk sharing in an infinite-horizon experiment. Economic Journal, 119:796-825.

Chaudhuri, A., Gangadharan, L., and Maitra, P. (2010). An experimental analysis of group size and risk sharing. Mimeo.

Cohen, A. and Siegelman, P. (2010). Testing for adverse selection in insurance markets. Journal of Risk and Insurance, The American Risk and Insurance Association, 77(1):39-84.

Cutler, D. M., Finkelstein, A., and McGarry, K. (2008). Preference heterogeneity and insurance markets: Explaining a puzzle of insurance. NBER Working Paper 13746, http://www.nber.org/papers/w13746.

Fehr, E. and Schmidt, K. (1999). A theory of fairness, competition and co-operation. Quarterly Journal of Economics, 114:817-868.

Fenger, M. (2009). Challenging solidarity? an analysis of exit options in social policies. Social Policy ES Administration, 43(6):649-665.

Fischbacher, U. (2007). Z-tree: Zurich toolbox for ready-made economic experiments. Experimental Economics, 10:171-178.

Greiner, B. (2004). An online recruitment system for economic experiments. In: Kurt Kremer, Volker Macho (Hrsg.): Forschung und wissenschaftliches Rechnen. GWDG Bericht 63. Ges. fr Wiss. Datenverarbeitung, Gttingen, pages 79-93.

Harrison, G. and Cox, J. (2008). Risk Aversion in Experiments. Research in Experimental Economics Series. Emerald Books. 
Rawls, J. (1971). A Theory of Justice. Oxford: Oxford University Press.

Schlag, K. H. and van der Weele, J. (2009). Efficient interval scoring rules. Universitat Pompeu Fabra Working Paper 1176.

Selten, R. and Ockenfels, A. (1998). An experimental solidarity game. Journal of Economic Behavior and Organization, 34:517-539.

Wakker, P. (2008). Explaining the characteristics of the power (CRRA) utility family. Health Economics, 17:1329-1344.

Wakker, P. (2010). Prospect Theory for Risk and Ambiguity. Cambridge: Cambridge University Press. 


\section{A Additional regression analysis}

We observe that the more individuals with lottery type 2 expect the 'good' risk lottery type to share, the more they share themselves. This can be seen from the regression results below. The dependent variable is lottery type 2's risk sharing level. The variable Belief_goodrisk is lottery type 2's belief about the sharing level of the good risk type.

Table 2: Effect of anticipated risk sharing of 'good' risk type on lottery type 2's sharing decision

\begin{tabular}{lcc}
\hline \hline Variable & Coefficient & (Std. Err.) \\
\hline$H E \mu \delta$ & -8.826 & $(5.596)$ \\
$H E \mu$ & -9.815 & $(6.470)$ \\
Gender & -4.220 & $(4.482)$ \\
Age & 1.006 & $(1.093)$ \\
Belief_goodrisk & $0.488^{* *}$ & $(0.097)$ \\
Intercept & 32.496 & $(24.612)$ \\
\hline $\begin{array}{l}\text { Note: }{ }^{* *} \text { 5\% significance level; treatment } H O \text { not included; treatment } \\
H E \delta \text { is the omitted treatment category; session dummies included but } \\
\text { not reported. }\end{array}$
\end{tabular}

\section{B Experimental Instructions}

\section{B.1 Risk Sharing Part}

[Instructions Part 1]

On the following screens you will be informed about the lottery that is randomly assigned to you as well as the lotteries that are randomly assigned to the other two group members.

You will be asked what percentage of your lottery outcome you put into the group account. When making this decision your lottery outcome and the other participant's lottery outcomes have not yet been randomly determined. The other two group members are faced with the same decision situations. The earnings in a decision situation will depend on all group members decisions in the way just described in the practice examples.

You will be asked to report your best guesses of how each of the other two members will decide. Specifically, for each other member you will be asked to report the interval in which you believe their decisions will lie. That is, you will report your best guess of the smallest and largest percentage each of the other two will put into the group account. With these guesses you can earn extra money and you will earn the more money the more accurate your guess is. 
Your earnings from this task are determined in the following way: If another's actual chosen percentage is outside your guessed interval (that is, is smaller than your smallest guess or larger than your largest guess) then you earn nothing with your guess. If another's actual chosen percentage is inside your guessed interval (that is, is equal or larger than your smallest guess and equal or smaller than your largest guess) then you earn the more the smaller your chosen interval is. For instance, if you guess one particular percentage $Z \%$ (the interval $Z \%-Z \%$ ), and the other member indeed puts this particular percentage $Z \%$ into the group account then you earn the maximal amount of 15 ECU with your guess. If you guess that the percentage will lie in the interval $0 \%-100 \%$ then you will earn 0 ECU. For intermediate intervals you earn in proportion to the length of the interval. For example, if you choose $28 \%-48 \%$ and the other's chosen actual percentage is $32 \%$ (that is, inside the interval) then you earn $15-15 *((48-28) / 100)=15-15 * 0.2=12$ ECU; if you would have chosen $16 \%-67 \%$ you would have earned $15-15 * 0.51=7.35 \mathrm{ECU}$.

The total earnings are the sum of your earnings resulting from your and the others actual decisions and the earnings resulting from your guesses.

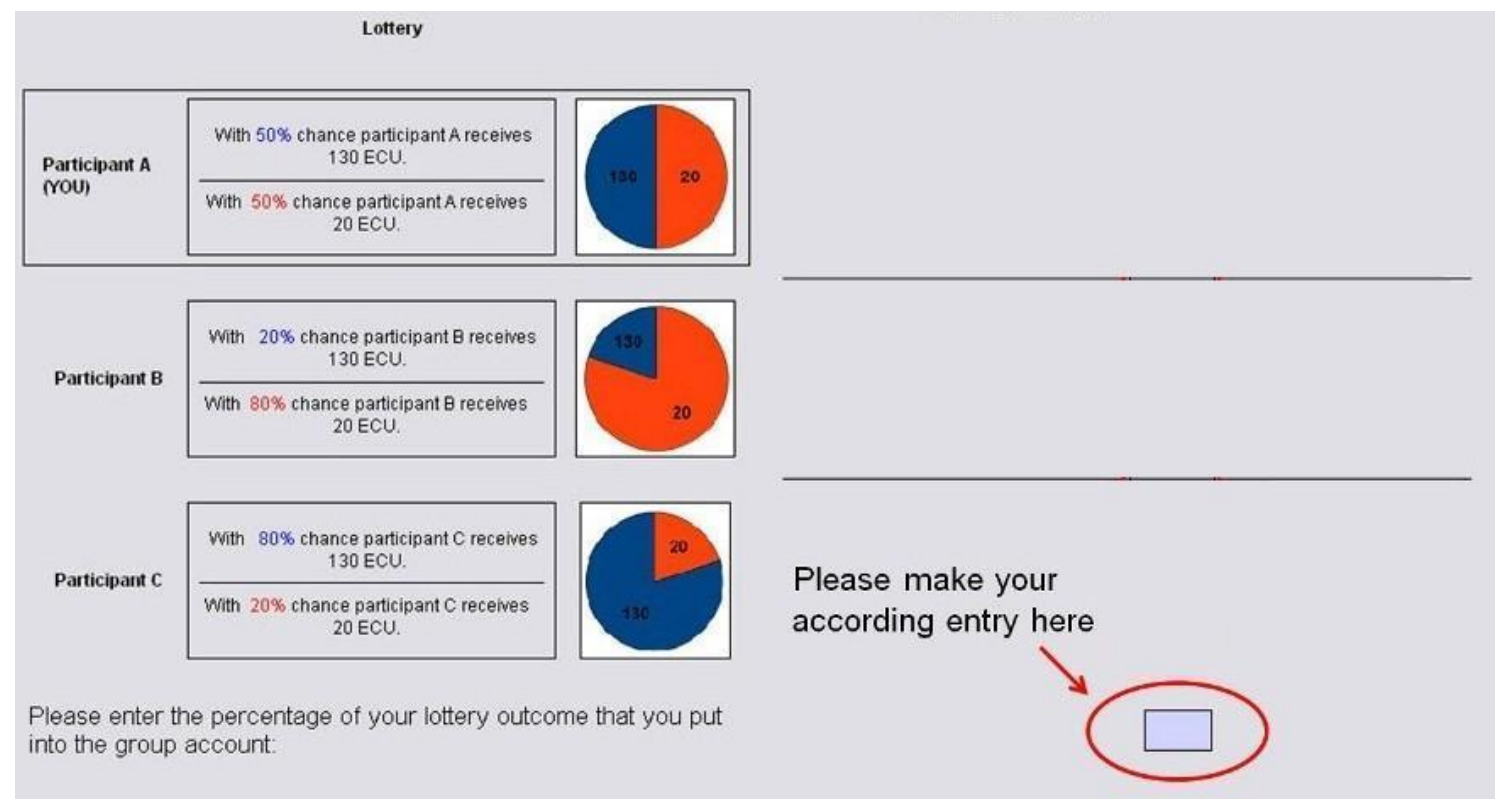

This is an example screen shot of the first decision task. You are not asked to make choices now! Please have a careful look. In this example you are participant A. You are asked to enter in the field below, emphasized by the red round frame, what percentage of your lottery outcome you want to put into the group account.

This is an example screen shot of the second decision task. You are not asked to make choices 


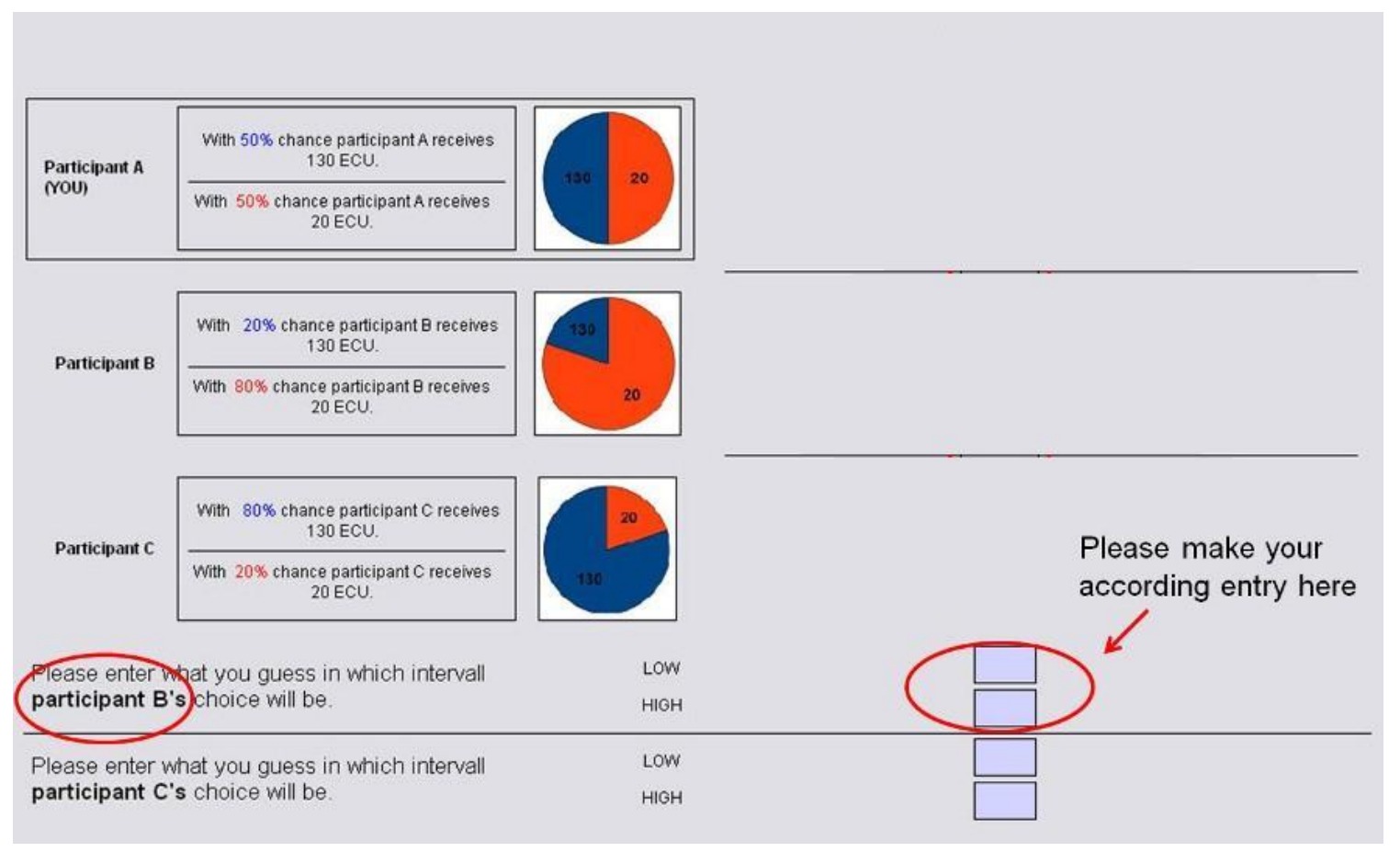

now! Please have a careful look. In this example you are asked to enter in the field emphasized with the red round frame, what you think in which interval participant B's choice X will be in that particular decision situation. In the field next to 'LOW' you enter the lower bound of the interval, in the field next to 'UP' you enter the upper bound of the interval. Take care that you don't exchange them! You do the same for the guess about participant C's decision below.

You now enter the actual decision stage! The entries you make on the next screens will be relevant for your payment.

\section{- Decisions for part 1 are made -}

\section{[Instructions Part 2]}

You are now again matched with two other participants and confronted with the same decision situation as on the previous screens. However, this time you face a different lottery than in the first part. Notice that you will not be with the same participants in one group again! The entries you make on the next screens will be relevant for your payment as well. The resulting earnings will be added to your earnings from the first part.

\section{- Decisions for part 2 are made -}

\section{[Instructions Part 3]}

You are now again matched with two other participants and confronted with the same decision situation as on the previous screens. However, you face a different lottery than in the first two 
parts. Notice that again you will not be with the same participants in one group twice! The entries you make on the next screens will be relevant for your payment as well. The resulting earning will be added up to your earnings from the first and second part.

- Decisions for part 3 are made - 


\section{B.2 Risk Elicitation Part}

You are now going to make another series of choices. These choices will not influence your earnings from the choices you just made, nor will your earlier choices influence the earnings from the choices you are going to make. After you have made these choices you will be asked to answer some questions. Thereafter the experiment will be over. In the following, you will be confronted with a series of 7 decision situations that will appear in random order on the screen. All these decision situations are completely independent of each other. A choice you made in one decision situation does not affect any of the other following decision situations.

Each decision situation is displayed on a screen. The screen consists of 20 rows. You have to decide for every row whether you prefer option A or option B. Option A is a lottery and is the same for every choice in a given decision situation, while the secure option B takes 20 different values, one for each choice.

\begin{tabular}{|c|c|c|c|}
\hline $\begin{array}{l}\text { DECISION } \\
\text { STIUATION } 5 .\end{array}$ & $\begin{array}{l}\text { OPTION A } \\
\text { LOTTERY }\end{array}$ & YOUR CHOICE & $\begin{array}{l}\text { OPTION B } \\
\text { SURE AMOUNT }\end{array}$ \\
\hline choice 1 & \multirow{20}{*}{$\begin{array}{l}\text { With } 20 \% \text { chance you receive } 130 \mathrm{ECU} \text {, } \\
\text { with } 80 \% \text { chance you receive } 20 \mathrm{ECU}\end{array}$} & $A \subset \subset B$ & $130 \mathrm{ECU}$ \\
\hline choice 2 & & $A \subset \subset B$ & $125 \mathrm{ECU}$ \\
\hline choice 3 & & $A \subset C B$ & $120 \mathrm{ECU}$ \\
\hline choice 4 & & $A \subset C B$ & $115 \mathrm{ECU}$ \\
\hline choice 5 & & $A \subset \subset B$ & $110 \mathrm{ECU}$ \\
\hline choice 6 & & $A \subset C B$ & $105 \mathrm{ECU}$ \\
\hline choice 7 & & $A \subset C B$ & $100 \mathrm{ECU}$ \\
\hline choice 8 & & $A \subset C B$ & $95 \mathrm{ECU}$ \\
\hline choice 9 & & $A \subset C B$ & $90 \mathrm{ECU}$ \\
\hline choice 10 & & $A \subset \subset B$ & $85 \mathrm{ECU}$ \\
\hline choice 11 & & $A \subset C B$ & $80 \mathrm{ECU}$ \\
\hline choice 12 & & $A \subset C B$ & $75 \mathrm{ECU}$ \\
\hline choice 13 & & $A \subset C B$ & $70 \mathrm{ECU}$ \\
\hline choice 14 & & $A \subset C B$ & $65 \mathrm{ECU}$ \\
\hline choice 15 & & $A \subset C B$ & $60 \mathrm{ECU}$ \\
\hline choice 16 & & $A \subset C B$ & $55 \mathrm{ECU}$ \\
\hline choice 17 & & $A \subset C B$ & $50 \mathrm{ECU}$ \\
\hline choice 18 & & $A \subset C B$ & $45 \mathrm{ECU}$ \\
\hline choice 19 & & $A \subset C B$ & $40 \mathrm{ECU}$ \\
\hline choice 20 & & $A \subset C B$ & $35 \mathrm{ECU}$ \\
\hline
\end{tabular}

This is a screen shot of one arbitrarily chosen decision situation you are going to face. You are not asked to make choices now! Please have a careful look. At the end of the experiment one of the 7 decision situations will be randomly selected with equal probability. Once the decision situation is selected, one of the 20 rows in this decision situation will be randomly selected with equal probability. The choice you have made in this specific row will determine your earnings. Consider, for instance, the screen shot that you have just seen. Option A gives you a $20 \%$ chance to earn 130 ECU and a $80 \%$ chance to earn 20 ECU. Option B is always a sure amount, in this case ranging from $130 \mathrm{ECU}$ in the first row, to $35 \mathrm{ECU}$ in the 20th row. Suppose that the 12th row is randomly selected. If you would have selected option B, you would receive 75 ECU. If, instead, you would have selected option A, the outcome of the lottery determines your earnings. 
Please note that each decision situation has the same likelihood to be the one that is relevant for your earnings. Therefore, you should view each decision independently and consider all your choices carefully.

- Decisions for risk elicitation are made - 